\title{
An Analysis of Task Performance Outcomes through E-Accounting in Malaysia
}

\author{
Wan Zuriati Wan Zakaria (Corresponding Author) \\ School of Commerce \& Law, FABIE, CQUniversity, QLD, Australia \\ E-mail: w.wanzakaria@cqu.edu.au
}

Professor Dr. Sheikh F. Rahman

School of Commerce \& Law, FABIE, CQUniversity, Melbourne, Australia

E-mail: s.rahman@cqu.edu.au

Dr. Mohamed Elsayed

School of Commerce \& Law, FABIE, CQUniversity, QLD, Australia

E-mail: m.elsayed@cqu.edu.au

Received: August 22, 2011 Accepted: September 09, $2011 \quad$ DOI: 10.5296/jpag.v1i2.946

\begin{abstract}
The objective of the study is to investigate the impact of E-Accounting on task performance outcomes in public sector agencies (PSAs) in Malaysia. The target population for the study was the users of E-Accounting from the accounting, finance and budgeting departments of federal ministries and agencies in the administrative centres of Putrajaya, Kuala Lumpur and Selangor areas. Using the random sampling method, 643 questionnaires were distributed, but 399 were collected. A multiple regression model and Pearson correlation coefficient were used to test the hypotheses of the study. Results of the study show that the adoption of E-Accounting within public sector agencies in Malaysia has significantly improved the budgeting, accounting and reporting, and auditing and controlling task performance of the public sector agencies.
\end{abstract}

Keywords: E-Accounting, task performance, Malaysian public sector agencies. 


\section{Introduction}

The introduction of advanced information technology (IT) has changed the way that businesses or organisations conduct their businesses. The capabilities of IT have led to the introduction of various information systems, such as, accounting information system (AIS), manufacturing resource planning system (MRP) and human resource system (HRM) to manage the various aspects of a business (Kharuddin, Ashari, \& Nassir, 2010).

The proper use of this technology may create competitive advantage for most businesses and organisations in all fields, including accounting. As a single largest user of IT and purveyor of information for the organisation (A.Hall, 2007), the evolution of IT in accounting has transformed the accounting information flow within and outside the organisations. Previous inefficient traditional paper-based manual accounting methods caused some problems, such as, wrong data entry, slow and inefficient task performance and massive utilization of paper products. Lack of data security was also a major issue. But, the emergence of computer based IT (Kharuddin et al., 2010) has changed not only the accounting profession itself, but also the accounting information systems and practices (Jackling \& Spraakman, 2006). IT as a key resource in accounting and financial information processing (Salehi, Rostami, \& Mogadam, 2010) has enabled the tedious task of manual bookkeeping to be substantially eliminated through the implementation of computerised accounting information systems (Aziz, 2003).

In the public sector agencies (PSAs), the computerised system has been widely adopted and utilised over the years to help the agencies become as competitive as private sectors. For instance, the computerised accounting information system (AIS) in public sector agencies was developed to provide an important benchmark to improve budget planning and execution and to increase the efficiency of the financial management system. Using governmental computerised accounting systems, the public sector agencies may manage the public resources efficiently and provide more reliable and timely financial information to the Auditor General, the Federal and state parliaments, the general public and to external parties. However, with a poor accounting system, the agencies may experience serious problems in managing public resources, such as, excessive costs, significant downtime, lost employee morale, inaccurate and inconsistent data generation, confusion, and blame shifting within the organisation.

Therefore, in Malaysia, in helping the PSAs to discharge their responsibilities in an efficient, effective and responsive manner, they are encouraged to implement the system to carry out all routine accounting-related tasks for achieving effective financial controls and to promote accountability. As the system is fully integrated and allows for decentralised data entry, the system may improve decision-making process, quality of accounting information, performance evaluation, internal controls and facilitating company's transactions (Sajady et al., 2008). Additionally, the system not only helps government to control their finances, but can enhance transparency and accountability, reducing political discretion and act as a deterrent to corruption and fraud (Rodin-Brown, 2008). 
As the main objective of the system is to accomplish accounting function of the organisation, therefore, there is need for a study to be carried out to examine the impact of the system on the performance of accounting-related tasks as expected within the Malaysian PSAs. The accounting-related task performance or task performance outcome (TPO) is defined as the capability of the system to perform specific tasks with explicit outcomes. Such task may be budgeting, or accounting and reporting, or auditing or controlling. The effective system will help the users to perform all the tasks efficiently and effectively.

This study is carried out to evaluate the impact of computerised AIS, known as E-Accounting, on task performance outcomes (TFO) from the users' perspective. The paper starts with an in-depth review of available literature on the topic followed by a review of measuring the impact of AIS on task performance outcomes. The third section includes the measures of task performance outcomes and the fourth section develops the hypotheses and models of the study. The next section describes the research method and sample used within Malaysian public sector agencies (PSAs). The sixth section contains the results and findings of the study. The last section presents the conclusion.

\section{Literature Review}

With the development of IT, accounting processes and practices have departed from the traditional accounting with changes in budgeting, accounting and financial reporting. . A number of studies have attempted to examine the impact of specific IT/IS system on task performance outcomes (TFO). According to Agourram (2009), the impact on task refers to the extent to which information can influence and modify the tasks that are executed by the users. For the government or public sector agencies, the computerised AIS is normally designed to allow for decentralised data entry, data reliability, accuracy and generation of timely information, compliance with budget laws and other public finance rules and restrictions that require entirely different sets of accounting and reporting outcomes (Namogang, 2007). The system can store, organise and access all financial and approved budget information easily, and also complete inventories of financial assets and liabilities. Moreover, the system not only helps governments to control their finances, but can enhance transparency and accountability by reducing political discretion and acting as a deterrent to corruption and fraud (Rodin-Brown, 2008).

The study by Goodhue et al. (1995) on "task-system fit" concentrated on the degree to which an information system assists individuals in performing their tasks. In order to ensure positive impact of IT on user performance, there should be a good fit between the IT and user's tasks (Goodhue et al., 1995). They conclude that greater task/system fit will lead to improved performance as needed by the individual. Banker et al. (2002) analysed task-technology fit with audit professionals' tasks in the three aspects of supporting audit decision making, fulfilling the requirements of routine operations in audit engagements and fitting the business' needs. However, the tasks technology fit relates to how well the functionalities of the technology fits the needs and requirements of the users (Masrek, Karim et al. 2007). Jain et al. (2006) believe that the higher the degree of fit between the 
technology's functionalities and the requirements of the user's tasks, the higher the probability that technology will be used and will have a significant contribution to accomplishing certain or specific individual tasks.

Ling-fang (2007) claims that with the computerised AIS implementation, the accounting functions as well as internal operations of financial management of public agencies have been changed to enable the accountants to work more efficiently and conveniently to meet their needs. However, the computerised accounting system is likely to bring some uncertainties and risks to auditing, such as, auditing internal control, audit clues, audit technology, audit standards, audit quality, and on the auditors themselves (Ling-fang, 2007). According to Banker (2002), auditors, with less knowledge in the system will face problems as the system is likely to increase the difficulty of audit tasks and impact on auditors' performances and professionalism in different ways at different ranks. In financial reporting, the system has limited effect on the input data quality, which may lead recipients to believe in inaccurate accounting information (Heeks, 1998).

The use of IT systems in the organisation may also present some challenges for the accountants. As the technology offers the accountants a number of ways of extracting detailed and precise information, the risk of poor accountability and loss of confidentiality may increase (Jordan, 1999). As a computerised system is complicated, expensive and difficult to manage and maintain, this has had deleterious effects on the whole public financial management systems that can cause unreliable revenue and expenditure data for budget planning, monitoring, expenditure control and reporting (Diamond, 2006; Rodin-Brown, 2008). These problems have resulted in the poor management of public resources with a large build-up of arrears, excessive borrowing, high interest rates and crowding out private sector investments, misallocation of resources, undermining of effectiveness and efficiency of service delivery (Diamond, 2006). Thus, the public sector agencies (PSAs) need appropriate planning, communication and change of management style to implement the computerised system effectively and successfully (Rodin-Brown, 2008).

There is a limited number of previous accounting studies related to the impacts of AIS. For instance, Chang et al. (2003) and Molanazari et al. (2010) examine the effects of task uncertainty, decentralisation and AIS characteristics with AIS performance. Aziz (2003) examines the correlation between the number of tasks and job satisfaction. He has classified the specific task performed by accounting system into seven tasks which are financial reporting, divisional reporting, budgeting, performance measurement, asset maintenance, capital expenditure decision, and investment or project appraisal. All respondents have indicated that they performed financial reporting using computerized accounting system. Almost half of the respondents (46.5 percent) use accounting system for divisional reporting and budgeting. Other tasks, in the order of number of responses are performance measurement, asset maintenance and capital expenditure decision (Aziz, 2003). However, Aziz (2003) found no significant relationships between the number of tasks and job satisfaction but he believed that when accountants are satisfied with these tasks, they will also be satisfied with their jobs. 
In the E-Accounting context, tasks are more related to accounting tasks or accounting processes which are important to improve the financial management of organisations. As stated by Namogang (2007), the budgeting and accounting functions are complementary and closely integrated. Thus, the E-Accounting systems will cover budget preparation, budget execution, appropriation, funds allocations, recording/accounting of the payment process, abstracting and reporting of financial and accounting data of appropriate agencies (Usmani \& Faheem 2006)., However, Granlund (2007) finds that the relationship between IT and the accounting field has been studied relatively little. He suggests that future studies should incorporate IT issues into accounting and management control. IT as a central mediator might have significant direct and indirect impacts on the everyday accounting practices in the intra and inter-organisational practices.

\section{Measuring the Impact of AIS on Tasks Performance Outcomes (TFO)}

Various instruments have been used to measure or assess the impact of AIS. Most researchers have found difficulty in directly measuring the quality and effectiveness of AIS and they have suggested many approaches and indicators as indirect or surrogate measurement of AIS. However, this evaluation also has to be supplemented by subjective judgements (for example, see Saarinen, 1996; Hassan, 1999; Ilias, 2007; Seliem, 2003). Success or otherwise of the E-Accounting can be demonstrated through its contribution to financial management and government operations (ICGFM, 2008). Salehi et al. (2010) define the AIS is successful when it is widely used by one or more satisfied users, and improves the quality of their performance.

Furthermore, Raupeliene and Stabingis (2003) propose a model to measure the effectiveness of AIS from economic, technical and social aspects. They believe that using multi criteria analysis is more successful in practice when calculating common index of AIS effectiveness and increase reliability of evaluation. They also suggest that the models should be classified according to the criteria of: the purpose of evaluation, aspects of evaluation, suitability to use in various phases of life cycle of AIS, and the measures of effectiveness indexes. Sajady et al. (2008) suggest that the effectiveness of AIS can be evaluated by its impacts on improvement of decision-making process, quality of accounting information, performance evaluation, internal controls and facilitating company's transactions. Also, the system will be effective if the underlying budgetary and accounting systems are robust and well managed (Diamond, 2006).

\section{Hypotheses Development and Conceptual Model}

The above discussion provides a number of avriables to look for in any study of the effectiveness of computerized accounting. E-Accounting is an integrated computerised accounting information system that commonly includes several common modules that are related to each other, such as budgeting, accounting and reporting. Accounting is very broad and the use of E-Accounting, not only affects budgeting, accounting and reporting, but also 
auditing (Ling-fang, 2007; Songini \& Gnan, 1996; Yeunyong, 2007) and controlling functions. . E-Accounting is a vital tool in the public sector's financial management and has a direct impact on its accounting practice but has not yet been explicitly examined (Spathis, 2006). Therefore, this study examined the effectiveness of E-Accounting to the task performance outcomes in a comprehensive way as depicted in the model of the study in Figure 1. The following hypotheses were developed in the study to examine the impact of E-Accounting on those accounting-related task performance outcomes.

$\mathrm{H}_{1}$ : E-Accounting has a positive impact on budgeting task performance.

$\mathrm{H}_{2}$ : E-Accounting has a positive impact on accounting and reporting task performance.

$\mathrm{H}_{3}$ : E-Accounting has a positive impact on auditing task performance.

$\mathrm{H}_{4}$ : E-Accounting has a positive impact on controlling task performance.

$\mathrm{H}_{5}$ : There is a positive relationship between E-Accounting and overall task performance outcomes for the organisation.

\section{E-Accounting Impact}

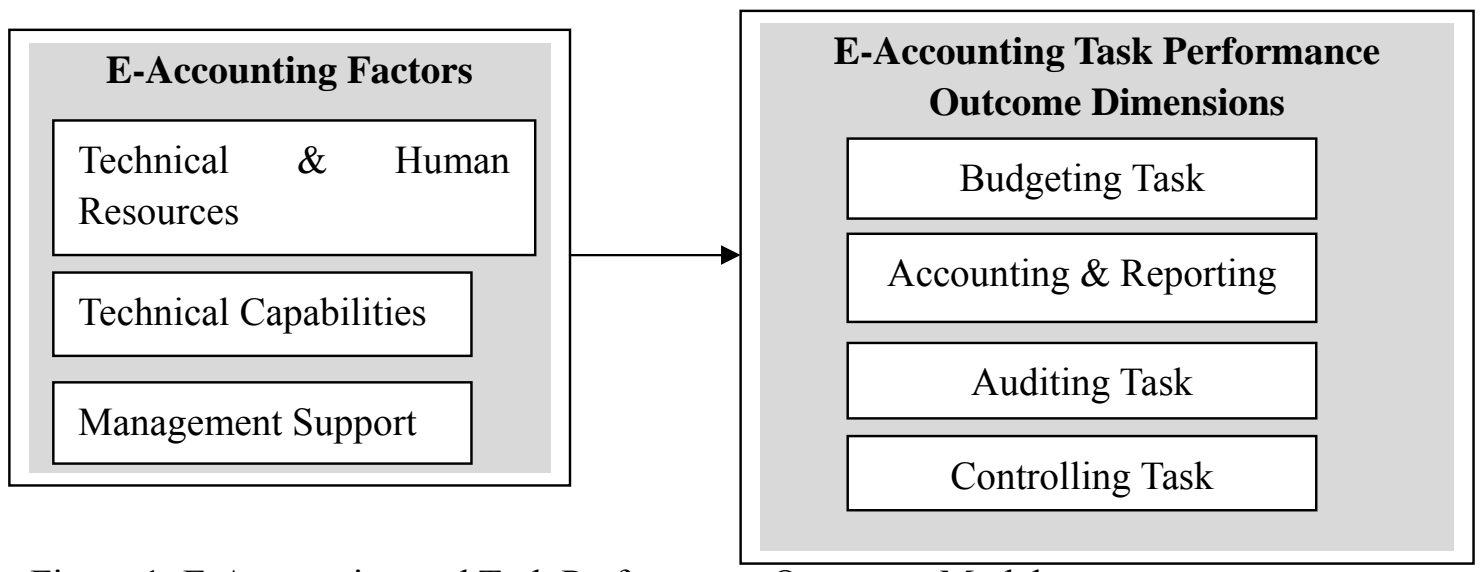

Figure 1: E-Accounting and Task Performance Outcomes Model

To test the hypotheses, a multiple regression analysis is applied to investigate the impact of E-Accounting on budgeting task performance; accounting and reporting task performance; auditing task performance and controlling task performance. Thus, a general multiple regression model was developed in this study as follows:

TASKi $=\beta_{0}+\beta_{1} T H R+\beta_{2} T C O+\beta_{4} M S+\alpha$

Where:

TASK $i=$ E-Accounting impact on the task performance outcomes

$\beta_{0} \quad=$ Constant (intercept)

THR $=$ Technical and human resources

TCO $=$ Technical capabilities 
MS $\quad=$ Management support

$\alpha \quad=$ the difference between the predicted and observed value of TASK (the error)

\section{Research Methodology}

\subsection{Population and Sample}

The population of the study consisted of individuals in accounting, finance or budgeting departments of federal ministries and agencies in Malaysia who are using or closely related to E-Accounting. Based on this sampling framework, a sample of 13 federal ministry departments and 55 federal agencies were selected from the targeted population. Using the random sampling method, a total of 643 questionnaires were distributed and 399 were collected, resulting in a sixty two percent response rate and 25 samples or four percent of the samples were rejected or discarded due to incomplete information and errors in responses.

\subsection{Measures}

In the study, the impact of E-Accounting on task performance outcomes; budgeting, accounting and reporting, auditing, and controlling were measured using a five-point Likert scale ( $1=$ "strongly disagree" to $5=$ "strongly agree"). There were 28 factors to measure task performance outcomes; consist of budgeting task performance outcomes (8 factors), accounting and reporting outcomes (9 factors), auditing and controlling outcomes (6 factors) and (5 factors), respectively. Besides, demographic data including gender, age, position in organization, accounting background, professional qualification, experience in current system, level of understanding and knowledge related to the system, were measured by different scales.

\subsection{Data Collection}

In accordance with the objective of the study, required data were collected to examine the impacts of E-Accounting on Malaysian PSAs from the users' perspective. The data were collected using a self-administered questionnaire through the Federal Government Administration Centre in Putrajaya, Kuala Lumpur and Selangor. The questionnaire had four sections to measure the variables of interest. The first section (section A) was about the adoption of E-Accounting in the organisation. The questions in section B asked respondents' detailed opinions on the impacts of E-Accounting on task performance outcomes (budgeting, 
accounting and reporting, auditing and controlling). The subsequent sections were constructed to seek respondents' opinions on the role of technical and human resources, technical capabilities and management support on the success of E-Accounting. In the last section, some demographical data, such as gender, age, current position, qualification were sought from the respondents to gain additional background information about the E-Accounting users who are participating in the survey. All questions in section B to C were framed on a five-point Likert scale.

\subsection{Validity and Reliability}

In determining the construct validity of the items, factor analysis was used in the study. Exploratory Factor Analysis (EFA) was employed in order to investigate possible dimensions underlying the original 40 items. The EFA is basically used to discover the nature of constructs influencing a set of responses. The study had 374 samples, which are suitable for EFA. Using the EFA, the data was separated into two parts to determine the underlying factor structures in the study. In the study, using the varimax extraction method, SPSS was extracted and revealed the presence of four-factors for rotation, with eigenvalues of 1 or greater and perfectly in line with the dimensions of E-Accounting performance outcomes suggested by the study. The result showed that all of the variables fit with the construct validity criteria and were used for the subsequent analysis.

The reliability is a measuring instrument to test consistency and stability of a set of scale items (Francis, 2004; Ho, 2006; Sekaran \& Bougie, 2010). The Cronbach's alpha is an adequate test of internal consistency and reliability in almost all cases (Sekaran \& Bougie, 2010), with the value between 0 and 1, but should be at least 0.7 and a value closer to 1 indicates more reliable (Francis, 2004). Therefore, the study conducted a reliability test to measure inter item correlation in each of the variables in the questionnaire. In relation to the independent variables, the Cronbach's alpha coefficient was .869 , dependant variable was .936 and for the overall instrument was .946 which approached the acceptable level of reliability. The Cronbach's alpha value for each of the accounting-related task performance outcomes is shown in Table 1. 
Table 1: The Result of the Reliability and Validity

\begin{tabular}{|lcccl|}
\hline Variables & Mean & Actual range & Factor loadings & $\begin{array}{l}\text { Cronbach's } \\
\text { Alpha }\end{array}$ \\
\hline Budgeting task performance & 3.83 & $3.75-3.98$ & $0.580-0.702$ & 0.853 \\
Accounting and reporting task & 3.94 & $3.84-4.19$ & $0.518-.0703$ & 0.889 \\
performance & & & & \\
Auditing task performance & 3.79 & $3.72-3.87$ & $0.683-0.814$ & 0.874 \\
Controlling task performance & 3.91 & $3.79-4.02$ & $0.585-0.759$ & 0.828 \\
\hline
\end{tabular}

\section{Findings}

The study examines the impact of E-Accounting and budgeting task performance; E-Accounting and accounting and reporting task performance; E-Accounting and auditing task performance; E-Accounting and controlling task performance.

\subsection{Correlation Analysis}

Table 2 provides correlation coefficients between dependent variables and independent variables (task performance outcomes). Overall, E-Accounting appears to have a significant and positive impact on all tasks performance outcomes: budgeting, accounting and reporting, auditing, and controlling task.

Table 2: The Result of Pearson Correlation

\begin{tabular}{|lrrrrrrrr|}
\hline & \multicolumn{1}{c}{ THR } & TCO & MS & BUD & ACC & AUD & CTR & ALL \\
\hline THR & 1 & & & & & & & \\
TCO & $0.660^{* *}$ & 1 & & & & & & \\
MS & $0.447^{* *}$ & $0.407^{* *}$ & 1 & & & & & \\
BUD & $0.366^{* *}$ & $0.417^{* *}$ & $0.445^{* *}$ & 1 & & & \\
ACC & $0.473^{* *}$ & $0.437^{* *}$ & $0.460^{* *}$ & $0.566^{* *}$ & 1 & & 1 \\
AUD & $0.414^{* *}$ & $0.406^{* *}$ & $0.406^{* *}$ & $0.482^{* *}$ & $0.638^{* *}$ & 1 & \\
CTR & $0.453^{* *}$ & $0.432^{* *}$ & $0.497^{* *}$ & $0.531^{* *}$ & $0.619^{* *}$ & $0.590^{* *}$ & 1 \\
ALL & $0.518^{* *}$ & $0.513^{* *}$ & $0.549^{* *}$ & $0.777^{* *}$ & $0.853^{* *}$ & $0.825^{* *}$ & $0.840^{* *}$ & 1 \\
\hline
\end{tabular}

\subsection{Hypotheses Testing}

To test the hypotheses of the study, multiple specified models according to the hypotheses developed were estimated that E-Accounting expected to show significant impact on all task performance outcomes. Consequently, the analysis included the overall task performance outcomes (ALL) and independent variables (THR, TCO and MS). Table 3 presents the summary of results of the multiple regression analysis in the study on the impact of E-Accounting to accounting-related task performance outcomes that were measured via technical and human resources factor, the technical capabilities factor and management support factor. 
Table 3: Summary Table of Multiple Regression Analysis

\begin{tabular}{|lrrrrr|}
\hline $\begin{array}{l}\text { Task Performance } \\
\text { Outcomes* }\end{array}$ & P-value & F-value & $\mathrm{R}^{2}$ & Adjusted $\mathrm{R}^{2}$ & $\begin{array}{c}\text { SE of } \\
\text { regression }\end{array}$ \\
\hline BUD & 0.000 & 44.891 & 0.267 & 0.261 & 0.403 \\
ACC & 0.000 & 56.894 & 0.326 & 0.310 & 0.389 \\
AUD & 0.000 & 41.385 & 0.251 & 0.245 & 0.429 \\
CTR & 0.000 & 60.586 & 0.329 & 0.324 & 0.426 \\
ALL & 0.000 & 90.830 & 0.424 & 0.419 & 0.306 \\
\hline
\end{tabular}

*BUD: Budgeting Task Performance, ACC: Accounting \& Reporting Task Performance, AUD: Auditing Task Performance, CTR: Controlling Task Performance, and ALL: Overall Task Performance.

\subsubsection{The Impact of E-Accounting on Budgeting Task Performance Outcome}

The result indicates that in the regression equation consisting of technical and human resource (THR), technical capabilities (TCO) and management support (MS) as independent variables, and budgeting task performance as dependent variable, there is statistically significant positive linear relationship between E-Accounting and budgeting task performance at $\mathrm{p}<.001$ level $(\mathrm{F}=44.891)$. It shows that the E-Accounting has a positive impact budgeting task performance outcome. Thus, this hypothesis is supported.

\subsubsection{The Impact of E-Accounting on Accounting and Reporting Task Performance Outcome}

The Table 3 reveals that the relationship between THR, TCO and MS were positively and significantly associated with the accounting task performance outcome (ACCPER) at $p$ $\leq .001$ level $(\mathrm{F}=56.894)$. It means that the E-Accounting has improved the accounting and reporting task, and this hypothesis is accepted.

\subsubsection{The Impact of E-Accounting on Auditing Task Performance Outcome}

As presented in Table 3, regression analysis was employed to estimate parameter to test $\mathrm{H}_{4}$. The result indicates that THR, TCO and MS have positive correlation and are significantly associated with the AUDPER at $\mathrm{p} \leq .001$ level $(\mathrm{F}=41.385)$ and supported this hypothesis. This means that E-Accounting does impact the auditing task performance outcome.

\subsubsection{The impact of E-Accounting on Controlling Task Performance Outcome}

The correlations of THR, TCO and MS were positive and significantly associated with CTRPER. This means that this relationship is statistically significant between the E-Accounting and controlling task performance $(\mathrm{F}=60.586, \mathrm{p}<.001)$. The E-Accounting has a positive impact on controlling task performance and this hypothesis is accepted.

\subsubsection{The impact of E-Accounting on overall task performance outcome}

Table 4 shows that the correlation between E-Accounting and task performance outcomes is positive and statistically significant $(\mathrm{r}=0.648, \mathrm{p}<.001)$ with $64.8 \%$ of the variation in the task performance outcomes (as indicated by the R-Square value), and significant at $(\mathrm{P} \leq 0.01$ ), with the value of Beta $=.572, \mathrm{P} \leq .001$. This is enough to establish a cause - effect relationship 
between E-Accounting and overall task performance outcomes. The use of the E-Accounting has a significant impact on the overall task performance outcomes of the PSAs. So, the fifth hypothesis is also accepted.

Table 4: Correlation Coefficient*

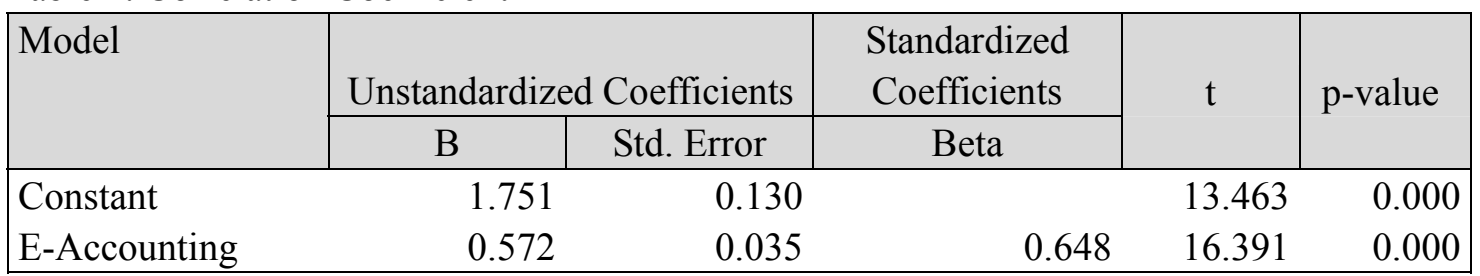

*Dependent Variable: Overall task performance

\section{Conclusions}

The results of the study provide strong evidence that the use of E-Accounting has contributed to the effectiveness of tasks as expected. The study shows that the use of E-Accounting may improve the effectiveness of accounting and reporting tasks, budgeting, controlling and auditing which may reflect on the organisational effectiveness as well. An improved quality in the system may provide better support for the tasks performed by the system. This study finds that the most significant impacts of E-Accounting are on accounting and reporting and budgeting task performance respectively. Therefore, this result is consistent with Aziz (2003) because the major tasks performed by the accounting system are financial reporting and budgeting.

The E-Accounting has a significant impact on budgeting tasks whereas the system has facilitated yearly budget proposals and project estimations. It also has improved planning/budgeting for the future and provides comprehensive performance information for management for the better future planning and public resources management. In the accounting and reporting task performances, the E-Accounting has significantly improved the recording process, strengthened financial control of PSAs, provided comprehensive financial condition and resources allocation information, and provided sufficient information for management and external users. For the auditing task performance, the E-Accounting also had a direct impact on the auditing tasks, such as, facilitating audit works to be done more efficiently and effectively with the available information. Moreover, the system is now able to provide all relevant audit information in a shorter time that may expedite audit trails, enhance auditor efficiency and professionalism for the effective audit. In the controlling task, the E-Accounting also has improved the controlling task by providing up to date and online data for the users that may eliminate data duplication and improve the centralised controlling of data system.

The evolution of IT in many of the PSAs has changed the way they conduct their businesses. But, the use of E-Accounting application still not widely applied in the PSAs, especially in developing countries, including Malaysia. Therefore, the findings of the study may provide better understanding of the current status of E-Accounting implementation and its significant 
contributions to the organizations and society, as well. The findings may also provide richer insights of the E-Accounting application to the public or stakeholders in evaluating the contribution of the system in creating the value of the organization. As the emergence of the technology has resulted challenges to the PSAs, the findings of the study should be considered by decision makers or policy makers to give the best benefit to the organization such as an input for the strategy formulation and planning in the future. The PSAs also should take into account the impact of the system seriously with considering on the management and employees attach to the system itself. They have a significant role for the effectiveness and successful of the system to accomplish the objectives of the system.

On the other hand, the PSAs who have already implemented the system should exploit the available system as much as possible to give the best benefits to organizations. With the significant amount of investments on the implementation of the system, the PSAs may realize that the system has positively improved the efficiency of the overall financial management processes. They also require updating the current system to meet the need of the users to maintain the process and service efficiency in the organizations. In addition, they promote the technology readiness between governments' bodies. Other PSAs who are still not implementing the system may use the findings of the study as an evidence of the success of the system; this may encourage them to implement the system in their organizations for the effectiveness and efficiency of financial administration processes and also to improve their accounting systems and practices. In addition, the organizations have been forced to develop new strategies to adapt with the demand of the technology and also to get the best result to the organizations with some changes in the accounting processes.

This study has its limitations. In examining the impacts of E-Accounting on task performance outcomes, only a few factors were highlighted in this study. As some other factors may also influence the impact of E-Accounting on the effectiveness of tasks performed by the system, those factors also need to be included in any future study. Also this study only involved E-Accounting users in federal ministries and agencies. Further studies should include other agencies, such as, state and local authorities and compare the performance of E-Accounting between the agencies. 


\section{References}

A. Hall, J. (2007). Accounting information systems. Quebec, Canada: Thomson Higher Education.

Agourram, H. (2009). Defining information system success in Germany. International Journal of Information Management, 29, 129-137.

http://dx.doi.org/10.1016/j.ijinfomgt.2008.05.007

Aziz, K. (2003). Accounting information system satisfaction and job satisfaction among Malaysian accountants. Paper presented at the 7th Pacific Asia Conference on Information Systems (PACIS), Adelaide, Australia.

Banker, R. D., Chang, H., \& Kao, Y.-C. (2002). Impact of information technology on public accounting firm productivity. Journal of Information Systems, 16(2), 209-222.

http://dx.doi.org/10.2308/jis.2002.16.2.209

http://dx.doi.org/10.2308/jis.2002.16.2.227

Chang, R.-D., Chang, Y.-W., \& Paper, D. (2003). The effect of task uncertainty, decentralization and AIS characteristics on the performance of AIS: an empirical case in Taiwan. Journal Information and Management, 40(7).

Chene, M. (2009). The implementation of integrated financial information management systems (IFMIS): Transparency international.

Dalci, I., \& Tanis, V. N. (2002). Benefits of computerized accounting information systems on the JIT production systems. Review of Social, Economic \& Business Studies, 2, 45-64.

Diamond, J., \& Khemani, P. (2006). Introducing financial management information systems in developing countries. OECD Journal on Budgeting, 5(3), 97-132.

http://dx.doi.org/10.1787/budget-v5-art20-en

Elpez, I., \& Fink, D. (2006). Information systems success in the public sector: Stakeholders' perspectives and emerging alignment model. Issues in Informing Science and Information Technology, 3, 219-231.

Granlund, M. (2007). On the Interface Between Management Accounting and Modern Information Technology: A Literature Review and Some Empirical Evidence. Working Paper.

Hassan, S. Z., \& Saeed, K. A. (1999). A framework for determining IT effectiveness: An empirical approach. Paper presented at the Hawaii International Conference on System Science. 
Heeks, R. (1998). Information systems and public sector accountability. Manchester, United Kingdom: Institute for Development Policy and Management.

ICGFM. (2008). Use of financial management information systems (FMIS) to improve financial management and accountability in the public sector. International Journal on Governmental Financial Management, 8(2), 162-173.

Ilias, A., Yasoa, M. R., Abd Razak, M. Z., \& Abdul Rahman, R. (2007). The study of end-user computing satisfaction (EUCS) on computerised accounting system (CAS) among Labuan F.T. government sectors: A case study in the responsibility centres. Labuan e-Journal of Muamalat and Society 1(2007), 1-13.

Jackling, B. and G. Spraakman (2006). The impact of Enterprise Resource Planning Systems on management accounting : An Australian study. International Conference on Accounting and Finance in Transition (ICAFT), Adelaide, Australia.

Jain, V. and S. Kanungo (2006). Performance impacts of IS at the individual level: An integrated model. European Conference on Information Systems (ECIS), Goteborg, Sweden.

Jordan, A. S. (1999). The impact technology is having on the accounting profession. Journal of Accounting Education, 17, 341-348.

http://dx.doi.org/10.1016/S0748-5751(99)00009-3

Kharuddin, S., Z. M. Ashari, et al. (2010). Information systems and firm's performance: The case of Malaysian small medium enterprises. Canadian Center of Science and Education, 3(4): 28-35.

Ling-fang, Z. (2007). Influences and countermeasures of computerized accounting on modern auditing. Journal of Modern Accounting and Auditing, 3(2), 77-81.

Maimbo, H., \& Pervan, G. (2001). A Model of IS/IT Investment and Organisational Performance in the Banking Industry Sector. Paper presented at the 12th Australasian Conference on Information Systems, New South Wales, Australia.

Masrek, M. N., N. S. A. Karim, et al. (2007). Antecedents and impact of intranet utilization: A conceptual framework. Journal of Information Technology Impact, 7(3): 213-226.

Molanazari, M., \& Abdolkarimi, E. (2010). The effects of task uncertainty, decentralisation and accounting information systems characteristics on the accounting information systems performance in Tehran stock exchange: Three ways interaction model. Paper presented at the 2nd International Conference on Information and Financial Engineering, Chongqing, China http://dx.doi.org/10.1109/ICIFE.2010.5609459 
Namogang, P. E. (2007). The report of the Auditor General on the government accounting \& budgetary system (GABS). Botswana: Office of the Auditor General.

Raupeliene, A., \& Stabingis, L. (2003). Development of a model for evaluating the effectiveness of accounting information systems. Paper presented at the EFITA Conference Debrecen, Hungary.

Rodin-Brown, E. (2008). Integrated financial management information systems: A practical guide. USAID-funded fiscal reform and economic governance project.

Saarinen, T. (1996). An expanded instrument for evaluating information system success. Journal of Information \& Management, 31, 103-118.

Sajady, H., Dastgir, M., \& Nejad, H. H. (2008). Evaluation of the effectiveness of accounting information systems. International Journal of Information Science and Technology, 6(2), 49-59.

Salehi, M., Rostami, V., \& Mogadam, A. (2010). Usefulness of accounting information system in emerging economy: Empirical evidence of Iran. International Journal of Economics and Finance, 2(2), 186-195.

Sekaran, U., \& Bougie, R. (2010). Research methods for business. United Kingdom: John Wiley \& Sons Ltd.

Seliem, A. A. M., Ashour, A. S., Khalil, O. E. M., \& Millar, S. J. (2003). The relationship of some organizational factors to information systems effectiveness: A contingency analysis of Egyptian data. Journal of Global Information Management, 11(1), 40-71.

http://dx.doi.org/10.4018/jgim.2003010103

Songini, L. and L. Gnan (1996). Information technology and the accounting department: The impact on activities and Accountant's Competencies. 19th Annual Congress of the European Accounting Association, Bergen, Norway.

Spathis, C. (2006). Enterprise systems implementation and accounting benefits. Journal of Enterprise Information Management, 19(2), 67-82.

http://dx.doi.org/10.1108/17410390610636887

Surmen, Y., \& Dastan, A. (2007). The relationship between the historical development of the accounting information system and its applications and information technologies. Paper presented at the Balkan countries' 1st International Conference on Accounting and Auditing.

Usmani, J. A. N. and M. Faheem (2006). Use of IT in audit country paper - Pakistan. Auditor General of Pakistan. 
Yeunyong, W. (2007). Causes and consequences of AIS effectiveness in manufacturing firms: Evidence from Thailand. International Journal of Business Research 7(6). 